\title{
Cone beam computed tomography investigation of the antral artery anastomosis in a population of Central Italy
}

\author{
S. Bernardi ${ }^{1}$, S. Mummolo', L.M. Ciavarelli², M. Li Vigni², M.A. Continenza' ${ }^{1}$, G. Marzo \\ ${ }^{1}$ Department of Life, Health and Environmental Sciences, University of L'Aquila, L'Aquila, Italy \\ 2 Private Practitioner, Pescara, Italy
}

[Received: 10 June 2015; Accepted: 28 July 2016]

Background: The arterial vascular supply of maxillary sinus has to be considered in all the surgical procedures where it is involved. In particular, the intraosseous anastomosis between the posterior superior alveolar artery and the infraorbital artery branches in the bony canal can be tricky to a not well aware clinician. The aim of this study is to investigate the arterial blood supply of the maxillary sinus to give clinicians the basis for a better understanding of vascular complications that can derive from surgical procedures at this level.

Materials and methods: One hundred cone beam computed tomography were analysed by the Imaging software for three-dimensional images, i-Dixel 2.0. The parameters considered have been the presence (i), the calibre (ii), the dorso-ventral length (iii) and the cranio-caudal distance (iv). The data have been processed with means, standard deviations and verified by T-Student test.

Results: The statistical outputs showed that the $38 \%$ of samples presented the intraosseous anastomosis. Those anastomosis resulted long in dorso-ventral way both on left $(12.55 \pm 4.3 \mathrm{~mm})$ and right side $(12.4 \pm 4.3 \mathrm{~mm})$. The mean cranio-caudal distance resulted $15.71 \pm 5.08 \mathrm{~mm}$ on the left and $14.73 \pm 4.74 \mathrm{~mm}$ on right side. The calibre measurements resulted quite big as well: $1.68 \pm 0.3 \mathrm{~mm}$ on the left and $1.54 \pm 0.38 \mathrm{~mm}$ on the right. The differences between the right and left sides were found not statistically significant.

Conclusions: This in vivo investigation shows how a knowledge of the maxillary sinus vascularisation is essential during the programming surgical phase in order to prevent blood complications during the operations involving this region. (Folia Morphol 2016; 75, 2: 149-153)

Key words: posterior superior alveolar artery, infraortbital artery, anastomosis, sinus vascularisation

\section{INTRODUCTION}

As well described by all anatomists, the vessels of nose region, maxilla and sinus walls constitute a rich network of arteries and veins. Branches of the ophthalmic, maxillary and facial arteries supply the nose. They form anastomotic plexuses within the nasal mucosa. The anterior and posterior ethmoidal branches of the ophthalmic artery supply the frontal and ethmoidal sinuses and the roof of the nose. The sphenopalatine branch of the maxillary artery supplies conchae, meatuses and posteroinferior part of the nasal septum being the principal vessel supplying the nasal mucosa. The greater palatine branch of the maxillary artery supplies the inferior meatus. Its terminal

Address for correspondence: S. Bernardi, D.D.S., Department of Life, Health and Environmental Sciences, University of L'Aquila, Via Vetoio 2, Coppito 2, 67100, L’Aquila, Italy, tel: +39 3479801726, e-mail: sara.bernardi@graduate.univaq.it 
part ascends through the incisive canal to anastomose on the septum with branches of the sphenopalatine and anterior ethmoidal arteries and with the septal branch of the superior labial artery. The pharyngeal branch of the maxillary artery supplies the sphenoidal sinus. The infraorbital artery and the superior, anterior and posterior alveolar branches of the maxillary artery supply the mucosa of the maxillary sinus. In particular, the maxillary artery passes through the pterygomaxillary fissure from the infratemporal fossa into the pterygopalatine fossa, where it terminates as the third part of the maxillary artery. This part of the artery gives branches running together with those of the maxillary nerve. The posterior superior alveolar artery arises from the maxillary artery and goes through the pterygomaxillary fissure into the maxillary tuberosity. It gives off several branches: some of them penetrate the bone to supply the maxillary posterior teeth and the maxillary air sinus, and the other branches supply the buccal mucosa. The infraorbital artery emerges into the face at the infraorbital foramen to supply the lower eyelid, part of the cheek, the side of the external nose, and the upper lip. During its route within the infraorbital canal it gives off the anterior superior alveolar artery directed downwards to supply the anterior teeth and the anterior part of the maxillary sinus $[1,6,9,19]$. Solar, together with his group, in 1999 was the first one to state and find out that those vessels were poorly described in classical textbooks of dental and human anatomy [18-20]. In his paper, he showed by a scheme, the course of the anastomosis between the posterior superior antral artery and the infraorbital anatomy. Then Elian et al. [7] in 2005, in his radiological study, observed how the computed tomography (CT) is not so sensitive comparing the data with the Solar et al. [18] and Traxler et al. [20] studies that were on human cadavers. However, he provided more data regarding the distribution and the position of the vascular anastomosis, and stated the factors of clinical significance: (i) the presurgical evaluation performed by CT scans were useful to spot the intraosseous vessel with a great diameter; (ii) the position of the osteotomy, indicating the safe distance as $15 \mathrm{~mm}$ from the alveolar bridge [7]. Mardinger et al. [13] in 2007, using the radiographic method, reported results slightly different from the former authors and how the vessels with a $<1 \mathrm{~mm}$ diameter do not represent a great risk or bleeding threat or obstacle during the surgical procedures. In 2009, Rysz et al. [17] studied the anastomosis on foetus cadavers, and clearly the results of the prevalence and distributions were different from the ones reported in the previous studies. Rosano et al. $[14,15]$ in 2009-2010 in cadaveric study confirmed the data reported by Solar et al. [18] and Traxler et al. [18] in 1999. Ilgüy et al. [11] in 2013 reported measures, septa presence and that the undetection of the anastomosis on cone beam CT (CBCT) is probably caused by the small diameter. The more recent study was by Rysz et al. [16] in 2014, which focused this time on adult CBCT scans. All of these authors reported different data and different methods, but all of them agree on two points:

1. The anastomosis supplies the lower part of the sinus, playing an important role in the graft integration and vascularisation;

2. Though its accidental sectioning is not life-threat, the bleeding can make difficult the visibility and the management of the Sneider's membrane.

The aim of this study is to report the prevalence, the distribution and the diameter of the antral artery anastomosis in an Italian population samples.

\section{MATERIALS AND METHODS}

One hundred CBCT were collected from a private dental clinic archive, in a central region of Italy. Patients were informed and gave their consent, but the personal details would not be revealed. The CTCB were made in order to plan a restorative-surgical treatment. All type of healthy patients were included in the study (non-edentulous, partially edentulous and total edentulous). The scans were analysed by the Imaging software for three-dimensional (3D) images, i-Dixel 2.0. The scans considered were the coronal and sagittal ones. 3D reconstructions were made as well (Figs. 1, 2). Only the interosseous anastomosis was analysed and the parameters considered have been the presence (i), the calibre (ii), the dorso-ventral length (iii) and the cranio-caudal distance from the vessel to the crest ridge or to the molar tooth apex (iv). For what concerns the last parameter, the distance was taken in the exact middle point. The data have been processed by XLSTAT software version 01.2015, with means, standard deviations and verified by T-Student test with a $\mathrm{p}$ value $<0.05$.

\section{RESULTS}

Among the 100 cases, 35 had the interosseous anastomosis; among those 35, 4 were just on the 

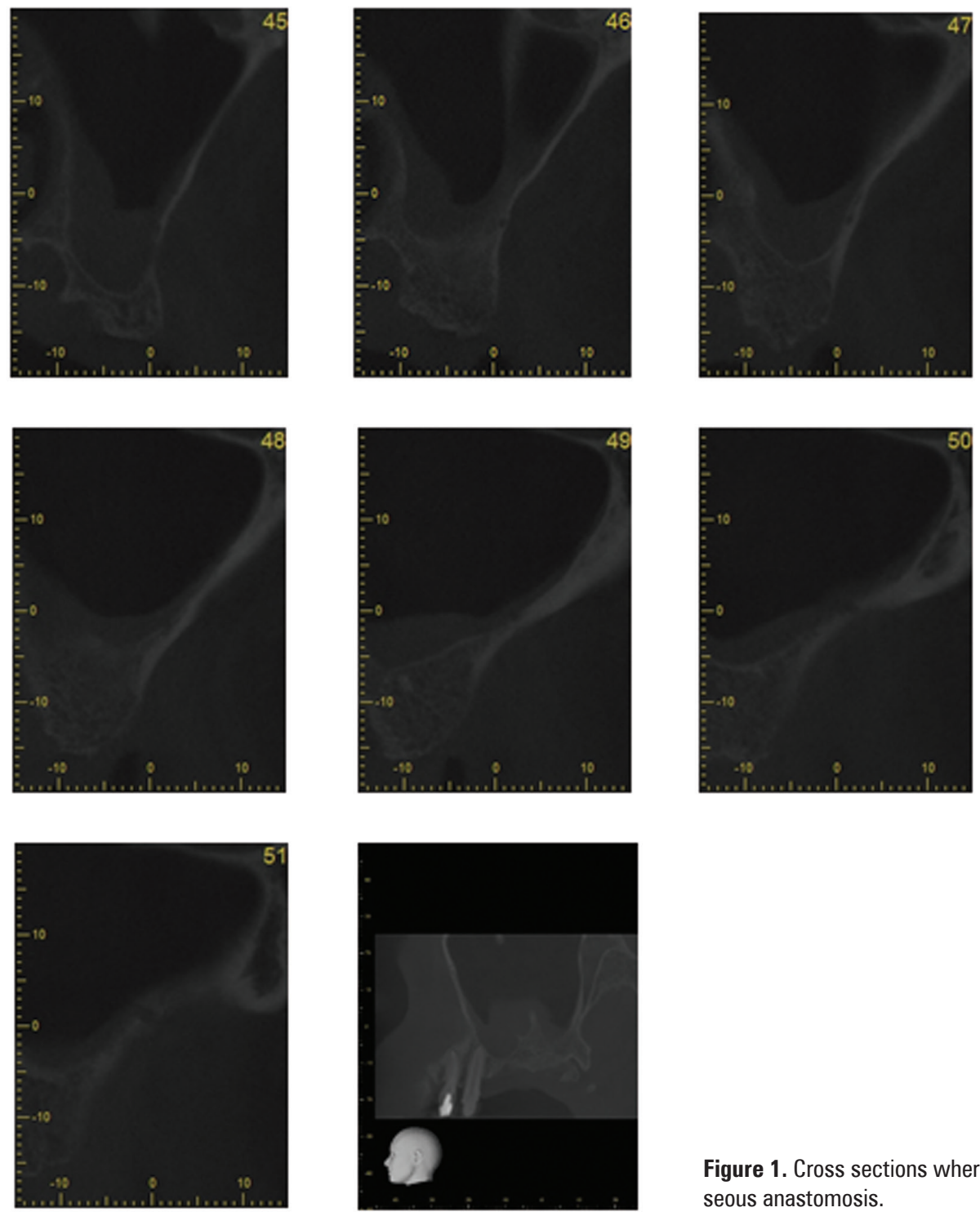

Figure 1. Cross sections where it is possible to note the intraoosseous anastomosis.
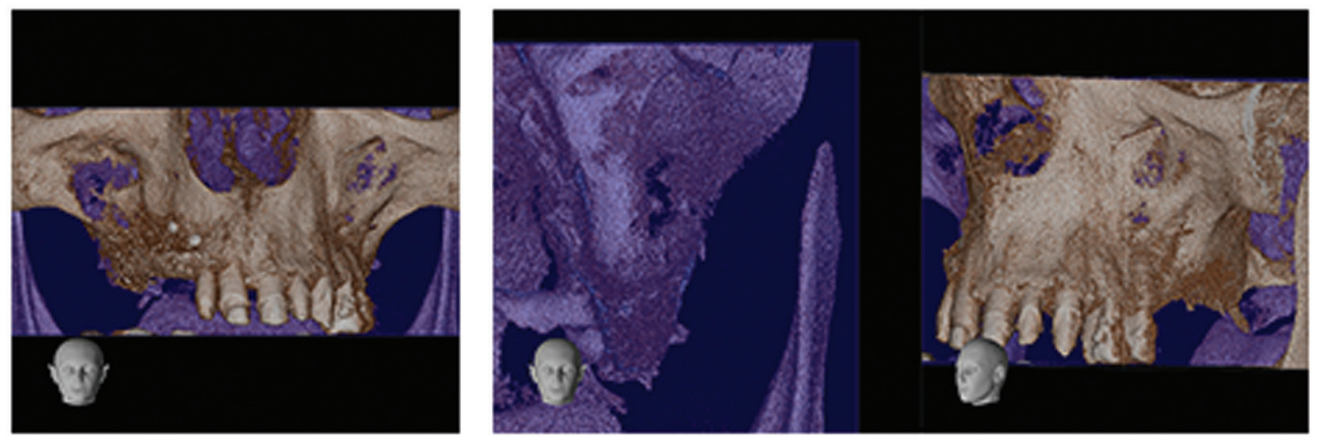

Figure 2. Three-dimensional reconstruction.

left sinus wall and 1 only on the right sinus (Table 1). Regarding the calibre, it resulted in a range $0.96-$ $-2.6 \mathrm{~mm}$ with a left side mean $1.681 \pm 0.372$ and right side $1.549 \pm 0.384 \mathrm{~mm}$. The length resulted in a range $4-27 \mathrm{~mm}$ with a left side mean $12.55 \pm 4.367 \mathrm{~mm}$ and right side $12.43 \pm 4.33 \mathrm{~mm}$. Cranio-caudal distance stayed in a range $6.5-26.76 \mathrm{~mm}$; a left side mean was $15.71 \pm 5.06$ and right side $14.73 \pm 4.74 \mathrm{~mm}$. 
Table 1. Frequency of the intraosseous anastomosis

\begin{tabular}{lcccc}
\hline Statistic & \multicolumn{3}{c}{ Frequency } \\
\hline No. of observations & 100 & & & Yes right \\
No. of categories & 4 & Yes & Yes left & 1.000 \\
Category & No & 33.000 & 4.000 & 1.000 \\
Frequency per category & 62.000 & 33.000 & 4.000 & \\
Rel. frequency per category (\%) & 62.000 & & & \\
\hline
\end{tabular}

Table 2. Measures of the considered parameters

\begin{tabular}{|c|c|c|c|c|c|c|}
\hline & Observations & Minimum & Maximum & Mean & $\begin{array}{l}\text { Standard } \\
\text { deviation }\end{array}$ & $\mathbf{P}$ \\
\hline \multicolumn{7}{|c|}{ Calibre } \\
\hline Left & 37 & 0.960 & 2.600 & 1.681 & 0.372 & $<0.0001$ \\
\hline Right & 34 & 0.970 & 2.370 & 1.549 & 0.384 & $<0.0001$ \\
\hline \multicolumn{7}{|c|}{ Length } \\
\hline Left & 37 & 5.000 & 27.000 & 12.553 & 4.367 & $<0.0001$ \\
\hline Right & 34 & 4.000 & 21.000 & 12.428 & 4.334 & $<0.0001$ \\
\hline \multicolumn{7}{|c|}{ Cranio-caudal distance } \\
\hline Left & 37 & 6.500 & 26.760 & 15.715 & 5.086 & $<0.0001$ \\
\hline Right & 34 & 6.560 & 25.390 & 14.736 & 4.745 & $<0.0001$ \\
\hline
\end{tabular}

Differences between left and right side were not statistically significant (Table 2).

\section{DISCUSSION}

The height and the thickness of crestal bone change relatively to the presence of the tooth and to the injuries can occur during a normal human life, such as endodontic and periodontal infections. In both of arches, it means that the restorative treatment by implants depends on the quantity and quality of residual bone, because of the presence of two noble anatomical structures: alveolar canal in the inferior jaw and the maxillary sinus in the upper jaw. The principal surgical technique to gain a height augmentation is the sinus floor lift procedure, with a lateral approach [4-12]. In this procedure, the knowledge of the vascular supply of this region is mandatory, to avoid unwanted haemorrhagic complications and to guarantee a good vascularisation of the grafted material $[2,3,5]$. Generally, during the surgical and grafting procedures in this region, the vessels involved are from the arterial anastomosis between the infraorbital artery and the posterior superior alveolar artery. Since Solar's group in 1999 provided a scheme and a more extensive anatomical point of view, many authors studied maxillary sinus anatomy and its vascularisation [18]. Solar and associates used cadavers, whereas Elian et al. [7] in 2005 used a more in vivo and clinical relevant method, the CT that is daily used by clinicians during the implant-prosthetic treatment planning. The two methods resulted in differences in the prevalence found by the two research teams. Solar found the anastomosis in the $100 \%$ of cases, whereas Elian found it in the $52.9 \%$. This difference is due to the fact the smallest arteries cannot be detected during the radiological investigations. In 2007 Mardinger et al. [13], using the CT scan method, was able to detect the anastomosis in $50 \%$ of the considered sample. Ilgüy et al. [11] in 2013, using the $C B C T$, had more rate of success in finding the anastomosis. Indeed the CBCT provides accurate and reliable linear measurement for imaging of dental and maxillofacial surgery. In 2014 Rysz et al. [16], found the anastomosis in $50 \%$ of his sample, using CBCT scans. Furthermore, the group focused on all type of patients than the edentulous, such as the formers. All of these authors affirm that the anastomosis forms a concave arch, with the lowest point located in the first molar area. In addition, they focused their results on the distance of the vessel from the alveolar ridge or the tooth, in many position for the whole length 
of the maxilla, reporting different data. In the study by Solar et al. [18], the intraosseous anastomosis was located 18.9-19.6 $\mathrm{mm}$ from the edge of the alveolar process. Ella et al. [8] reported the anastomosis to be located 3-13 mm from the edge of the lower alveolar. In a paper published by Hur et al. [10], the mean distance between the intraosseous anastomosis and the cervical line was $26.9 \mathrm{~mm}$ at the level of the first premolar, $24.1 \mathrm{~mm}$ for the second premolar, $21.1 \mathrm{~mm}$ for the first molar, $22.4 \mathrm{~mm}$ for the second molar, and $23.3 \mathrm{~mm}$ from the maxillary tuberosity. In the Rysz et al. study [16], the distance between the anastomosis and the cervical line of the first molar was 15-19 mm. In this study, the dentate and edentulous data were not distinguished, because the sample of found anastomosis was too small. We chose the apex as reference point because the centre of the crown, as chosen by llgüy et al. [11], or the cement enamel line were too distant, if compared with the ones found in the edentulous patients. However, the data reported in this study stay in the range of the ones found in literature. Furthermore, another parameter has been added that misses in the other studies: the length of the anastomosis which was found to be in a range of 12.4-12.5 mm. According to other authors, the reported data confirm the need for a deep knowledge of the anatomy of this region and the prescription of a $\mathrm{CT}$ before the intervention is fundamental both for a surgical procedure free of nasty complications, and for a better integration of the grafting material and the implant.

\section{CONCLUSIONS}

The arterial connection between the infraorbital artery and the posterior superior alveolar artery in the lateral wall of the sinus is not a variance but a rule. Knowing and spotting it before the surgical intervention of sinus floor lift augmentation is important in order to choose the best incision position, to avoid haemorrhagic incident and for a better graft integration.

\section{REFERENCES}

1. Anastasi G, Castano P, Castorina S, Cremona O, De Caro R, Gaudio E, Macchiarelli G, Rende M, Ribatti D, Sforza C, Tacchetti C (2014) Anatomia Umana - Atlante. Vol. 1-3. Milano edi Ermes.

2. Bell WH, Levy BM (1971) Revascularization and bone healing after posterior maxillary osteotomy. J Oral Surg, 29: 313-320.

3. Bell WH, You ZH, Finn RA, Fields RTh. (1995) Wound healing after multisegmental Le Fort I osteotomy and transection of the descending palatine vessels. J Oral Maxillofac Surg, 53: 1425-1433.

4. Bernardi S, Mummolo S, Li Vigni M, Ciavarelli Macozzi L, Zeka K, Giuseppe Marzo G, Continenza MA (2014) The antral artery anastomosis: an in vivo investigation. Italian J Anat Embriol, 119 (suppl. 1): 16.

5. Boyne PJ, James RA (1980) Grafting of the maxillary sinus floor with autogenous marrow and bone. J Oral Surg, 38: 613-616.

6. Brand RW, Isselhard DE (1990) Anatomy of orofacial structures. 4th Ed. C.V. Mosby, St. Louis: 171-177.

7. Elian N, Wallaces S, Cho SC, Jalbout ZN, Froum S (2005) Distribution of the maxillary artery as it related to sinus floor augmentation. Int J Oral Maxillofac Impl, 20: 784-787.

8. Ella B, Sedarat C, Da Costa Noble R, Normand E, Lauverjat Y, Siberchicot F, Caix P, Zwetyenga N (2008) Vascular connections of the lateral wall of the sinus: surgical effect in sinus augmentation. Int J Oral Maxillofac Impl, 23: 1047-1052.

9. Fonzi L (2000) Anatomia funzionale e clinica dello splancnocranio. Milano Edi Ermes.

10. Hur MS, Kim JK, Hu KS, Bae HE, Park HS, Kim HJ (2009) Clinical implications of the topography and distribution of the posterior superior alveolar artery. J Craniofac Surg, 20: 551-554.

11. Ilgüy D, Ilgüy M, Dolekoglu S, Fisekcioglu E (2013) Evaluation of the posterior superior alveolar artery and the maxillary sinus with CBCT. Braz Oral Res (São Paulo), 27: 431-437.

12. Marchetti E, Lopez MA, Confalone L, Mummolo S, Marzo G (2010) Maxillary sinus augmentation by crestal approach and ultrasound. Jour Oss, 2: 79-83.

13. Mardinger O, Abba M, Hirshberg A, Schwartz-Arad D (2007) Prevalence, diameter andcourse of the maxillary intraosseous vascular canal with relation to sinus augmentation procedure: a radiographic study. Int J Oral Maxillofac Surg, 36: 735-738.

14. Rosano G, Taschieri S, Gaudy JF, Del Fabbro M. (2009) Maxillary sinus vascularization: a cadaveric study. J Craniofac Surg, 20: 940-943.

15. Rosano G, Taschieri S, Gaudy J-F, Weinstein T, Del Fabbro M (2011) Maxillary sinus vascular anatomy and its relation to sinus lift surgery. Clin Oral Impl Res, 22: 711-715. doi: 10.1111/j.1600-0501.2010.02045.x.

16. Rysz M, Ciszek B, Rogowska M, Krajewski R (2014) Arteries of the anterior wall of the maxilla in sinus lift surgery. Int J Oral Maxillofac Surg, 43: 1127-1130.

17. Rysz M, Koleśnik A, Lewińska B, Ciszek B (2009) The study of arterial anastomoses in the region of the alveolar process and the anterior maxilla wall in fetuses. Folia Morphol, 68: 65-69.

18. Solar P, Geyerhofer U, Traxler H, Windisch A, Ulm C, Watzek G (1999) Bloody supply to the maxillary sinus relevant to sinus floor elevation procedure. Clin Oral Implants Res, 10: 34-44.

19. Standring S. (2007) Gray's anatomy, 39th Ed. Elsevier, Basel.

20. Traxler H, Windisch A, Geyerhofer U, Surd R, Solar P, Firbas W (1999) Arterial blood supply of the maxillary sinus. Clin Anat, 12: 417-421. 